\title{
Sumac Leaves as a Novel Low-Cost Adsorbent for Removal of Basic Dye from Aqueous Solution
}

\author{
Öznur Dülger, Fatma Turak, Kadir Turhan, and Mahmure Özgür \\ Chemistry Department, Yildiz Technical University, 34220 Esenler, Istanbul, Turkey \\ Correspondence should be addressed to Mahmure Özgür; mozgur@yildiz.edu.tr
}

Received 21 August 2013; Accepted 26 September 2013

Academic Editors: J. J. Santana-Rodríguez and N. Viswanathan

Copyright (C) 2013 Öznur Dülger et al. This is an open access article distributed under the Creative Commons Attribution License, which permits unrestricted use, distribution, and reproduction in any medium, provided the original work is properly cited.

Sumac Leaves (SL) (Rhus Coriaria L.) were investigated as an inexpensive and effective adsorbent for the adsorption of methylene blue (MB) from aqueous solution. The effects of initial dye concentration, initial solution $\mathrm{pH}$, phases contact time, and adsorbent dose on the adsorption of MB on SL were investigated. The amount of dye adsorbed was found to vary with initial solution $\mathrm{pH}$, Sumac Leaves dose, MB concentration, and phases contact time. The Langmuir and Freundlich adsorption models were evaluated using the experimental data and the experimental results showed that the Langmuir model fits better than the Freundlich model. The maximum adsorption capacity was found to be $151.69 \mathrm{mg} / \mathrm{g}$ from the Langmuir isotherm model at $25^{\circ} \mathrm{C}$. The value of the monolayer saturation capacity of SL was comparable to the adsorption capacities of some other adsorbent materials for MB. The adsorption rate data were analyzed according to the pseudo-first order kinetic and pseudo-second order kinetic models and intraparticle diffusion model. It was found that kinetic followed a pseudo-second order model.

\section{Introduction}

Dyes are widely used in many industries, such as textiles, leather, paper, printing, and cosmetics. In dyeing industry over 30-60 liters of water is consumed per $\mathrm{kg}$ of cloth dyed and large quantities of effluent are released during the process [1]. Presently there are over 450 mills with installed capacity of 20.2 million tons (MT) with average size of 2150 total producing days (TPD) with some units of 10000 TPD and few of 5000 TPD [2]. The textile industry alone accounts for two thirds of the total dyestuff production, about 10$15 \%$ of the dyes used come out through the effluent. Nearly $10-15 \%$ of the synthetic textiles dyes, used yearly, are lost to waste streams and about $20 \%$ of these waste enter the environment through untreated or ill-treated effluent from inefficient treatment plants. Consequently, their wastewater effluents are highly colored and the disposal of these into receiving waters causes damage to the environment as they may significantly affect photosynthetic activity in aquatic life due to reduced light penetration. The release of colored wastewater from these industries may present an ecotoxic hazard and introduce the potential danger of bioaccumulation, which may eventually affect man through the food chain
[3]. Dyes are almost invariably a visible pollutant, so their removal from effluents, to be added to fresh water bodies, is ecologically essential. Color removal from textile effluents is a major environmental problem concerning these days because of the difficulty of treating such streams by conventional wastewater systems. Various techniques like precipitation, ion exchange, chemical oxidation, and adsorption have been used for the removal of toxic pollutant from wastewater. Among these methods adsorption is widely used for dye removal from wastewaters [4]. Although activated carbon is the most effective adsorbent for adsorption of dye, it is quite expensive and also has problems associated with regeneration, which has necessitated the search for alternate low cost biodegradable and efficient adsorbent. Recently, there have been several reports on the economic removal of dyes using adsorbents such as hen feathers [5], lemon peel [6], jute fibre [7], pineapple stem [8], and raw Posidonia oceanica fibres [9]. Methylene Blue (MB) adsorption on various adsorbents has been studied by many researchers. Among these materials adsorption of $\mathrm{MB}$ was investigated by $[3,4,7,9]$. Recently, the interest on biomaterials and especially tannins was growing and some attractive results were obtained in the adsorption of some metals by tannin 

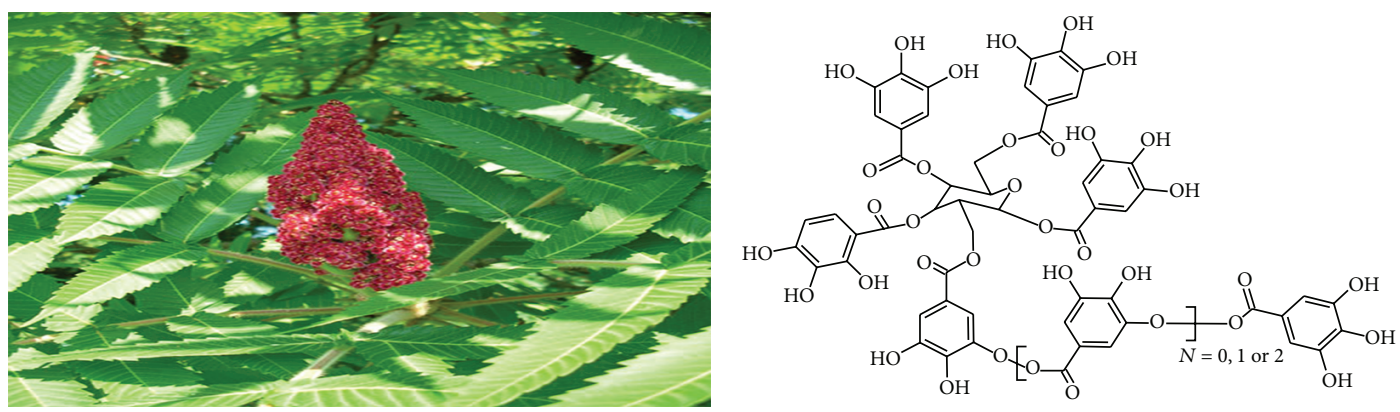

FIgURE 1: Sumac (Rhus Coriaria L.) and chemical structure of Turkish Sumac tannin.

adsorbents [10]. Tannins are widely distributed in nature and have multiple adjacent polyhydroxyphenyl groups in their chemical structure which have extremely high affinity for heavy metal ions [11], all proteins, and other macromolecules like polysaccharides. Sumac Leaves (Rhus Coriaria L.) (SL) are a shrub which reach $3-4 \mathrm{~m}$ in height in the wild. The main compounds present in Rhus family are hydrolysable gallotannins. Turkish sumac tannin (hydrolysable tannins) is illustrated in Figure 1 whose basic structure is of flavan-3-ols [12].

In present study, Sumac Leaves (SL) were considered for the treatment of aqueous solution because of two significant reasons: firstly, sumac tree widely grew in the high lands of our country and thus the adsorbent can be prepared and used wherever the problem exists and secondly Sumac Leaves contain hydrolysable gallotannins which are highly beneficial due to their properties like antibacterial, antimicrobial, antibite, and anticorrosive in nature [13]. MB is selected as a model compound for evaluating the potential of Sumac Leaves to remove dye from wastewaters. MB is a cationic dye, which is most commonly used for coloring paper, temporary hair colorant, dyeing cottons, wools, and so on. This dye is not strongly hazardous, but it can cause some harmful effects.

The aim of this study was to investigate the potentiality of Sumac Leaves as a novel low cost adsorbent for the adsorption of MB dye. Therefore the effects of initial MB concentration and solution $\mathrm{pH}$, phases contact time, and adsorbent dose were investigated. Adsorption isotherms and kinetics parameters were also calculated and discussed.

\section{Materials and Methods}

2.1. Preparation of Adsorbent. The Sumac Leaves used were collected from around Manisa city (Turkey) and were dried at room temperature and darkness. They were grounded and sieved, and the fraction of particles smaller than $300 \mu \mathrm{m}$ was used for adsorption studies. Samples were stored in an airtight plastic container and in dark conditions.

2.2. Reagents. A monovalent cationic dye, $\mathrm{MB}$, was selected for adsorption studies. It is classified as CI Basic Blue 9, CI Solvent Blue 8, and CI 52015. The molecular formula is $\mathrm{C}_{16} \mathrm{H}_{18} \mathrm{~N}_{3} \mathrm{SCl}$ and the molecular weight is 319.86 . The chemical structure of dye is shown in Figure 2.<smiles></smiles>

FIgURE 2: Chemical structure of MB.

2.3. Apparatus. The dual beam UV-Visible spectrophotometer (Shimadzu UV-1800 PC, USA) connected to an IBM compatible personal computer (PC) and a HP-P1102 Laser jet printer was used for all absorbance measurements with a $1 \mathrm{~cm}$ quartz cells.

The $\mathrm{pH}$ value in all experiments was measured, A Hach Sension $\mathrm{pH}$-meter PH3 (Crison, Spain), and orbital shaker (Wises stir MS-MP8, Korea) was used for the batch experiments. The adsorbent was separated using centrifugation (Centurion Scientific C2, Centurion, England).

2.4. Batch Adsorption Studies. Adsorption experiments were carried out by adding a fixed dose of SL $(0,3 \mathrm{~g})$ to a series of $100 \mathrm{~mL}$ stoppered polyethylene conical flasks filled with $50 \mathrm{~mL}$ diluted solution $(100-900 \mathrm{mg} / \mathrm{L})$ of $\mathrm{MB}$ dye. The $\mathrm{pH}$ was adjusted to the desired value with $0,1 \mathrm{~N} \mathrm{NaOH}$ or $0,1 \mathrm{~N}$ $\mathrm{HCl}$ solutions. The conical flasks were then sealed and placed on an orbital shaker and shaken at $250 \mathrm{rpm}$ with a required time at $25^{\circ} \mathrm{C}$. After regular time intervals, the flasks were then removed from the shaker, and the solutions were centrifuged for $15 \mathrm{~min}$ at $6000 \mathrm{rpm}$. Final concentration of dye in the solution was measured at maximum wavelength of the dye solution $(665 \mathrm{~nm})$ by a UV/VIS spectrophotometer using a $1 \mathrm{~cm}$ quartz cell. The calibration curve was plotted between absorbance values and MB concentrations (1-7 mg/L). The regressive coefficient was 0.999 . The amount of dye adsorbed at equilibrium $q_{e}(\mathrm{mg} / \mathrm{g})$ was calculated from

$$
q_{e}=\frac{\left(C_{0}-C_{e}\right) \times V}{m},
$$

where $C_{0}$ and $C_{e}(\mathrm{mg} / \mathrm{L})$ are the initial and the equilibrium concentrations of dye in liquid phase, respectively. $V(\mathrm{~L})$ is the initial volume of dye solution and $m(\mathrm{~g})$ is the mass of 
the adsorbent. It can calculate, also, the percentage of dye retained using

$$
R \%=\frac{\left(C_{0}-C_{e}\right)}{C_{0}} \times 100,
$$

where $C_{0}$ and $C_{e}$ have the same definition described earlier.

The methodology of kinetic experiments was basically identical to those of equilibrium tests. The samples of supernatant were taken at preset time intervals and the concentrations of dye solution were similarly determined. The adsorption capacity at time $t, q_{t}(\mathrm{mg} / \mathrm{g})$ was calculated using

$$
q_{t}=\frac{\left(C_{0}-C_{t}\right) \times V}{m},
$$

where $C_{e}$ is in this case $C_{t}$-concentration at time $t$ and $q_{e}$ is $q_{t}$, respectively.

The experimental parameters studied are adsorbent dose $(0,1-0,5 \mathrm{~g})$, phases contact time (15-240 min), initial MB concentration (100-900 mg/L), and solution $\mathrm{pH}(2-9)$.

Each experiment was duplicated under identical conditions and the average values were used for the data analysis. Blank samples were run under similar experimental conditions but in the absence of adsorbent.

2.5. Effect of Adsorbent Dose. To observe the effect of SL dose on the adsorption of MB, SL samples (0.1-0.5 g) were shaken for $2 \mathrm{~h}$ with $50 \mathrm{~mL}$ solution with $\mathrm{MB}$ dye concentration ranging from 100 to $600 \mathrm{mg} / \mathrm{L}$.

2.6. Effect of Initial Solution $\mathrm{pH}$. The $\mathrm{pH}$ value of dye solution plays an important role in the whole adsorption process and particularly on the adsorption capacity [14]. A pH-meter equipped with a combine electrode was used for the $\mathrm{pH}$ measurements. To study the effect of $\mathrm{pH}$ solution, initial $\mathrm{pH}$ value was adjusted to $2,3,4,5,6,7,8$, and 9 by adding $0,1 \mathrm{~N}$ $\mathrm{HCl}$ or $0,1 \mathrm{~N} \mathrm{NaOH}$. The $\mathrm{pH}$ value was controlled at the end of adsorption process. The initial concentration of $\mathrm{MB}$ in the solution was $600 \mathrm{mg} / \mathrm{L}$ and the dose of SL was $0.3 \mathrm{~g}$. The system was shaken with a constant speed of $250 \mathrm{rpm}$ for 2 hours at $25^{\circ} \mathrm{C}$.

2.7. Equilibrium Studies. A fixed dose of adsorbent ( $0.3 \mathrm{~g})$ was added into a set of $100 \mathrm{~mL}$ stoppered conical flasks containing $50 \mathrm{~mL}$ of different initial concentrations $(100,150,200,250$, $500,600,700,800$, and $900 \mathrm{mg} / \mathrm{L}$ ) of $\mathrm{MB}$ dye solution. $\mathrm{pH}$ of the solution was adjusted to 7. The flasks were shaken at $250 \mathrm{rpm}$ and $25^{\circ} \mathrm{C}$ for $2 \mathrm{~h}$.

2.8. Kinetic Studies. The methodology of kinetic experiments was basically identical to those of equilibrium tests. The samples of supernatant were taken at different time intervals and the concentrations of MB were similarly determined. The experiments of adsorption kinetic were investigated using the same adsorption technique: the $0.3 \mathrm{~g}$ of dry SL was contacted with $50 \mathrm{~mL}$ of $\mathrm{MB}$ dye solution having $600 \mathrm{mg} / \mathrm{L}$ concentration. The systems were continuously shaken at $250 \mathrm{rpm}$ at $25^{\circ} \mathrm{C}$. Samples were withdrawn, at preset time intervals, and then centrifuged at $6000 \mathrm{rpm}$ for $15 \mathrm{~min}$ and the absorbance value of supernatant was measured.

\subsection{Theory}

2.9.1. Isotherm Models. Adsorption isotherms describe how pollutants interact with adsorbent materials and so they are critical in optimizing the use of adsorbents. In order to optimize the design of an adsorption system to remove dye from solutions, it is important to establish the most appropriate correlation for the equilibrium curve. There are several isotherm models available for analyzing experimental adsorption equilibrium data [15]. The most common adsorption models used to fit the experimental data were Langmuir and Freundlich [6, 16-18]. The Langmuir model which assumes that equilibrium is attained when a monolayer of the adsorbate molecules saturates the adsorbent has the following linear form:

$$
\frac{C_{e}}{q_{e}}=\frac{1}{K_{L}}+\frac{a_{L} C_{e}}{K_{L}},
$$

where $C_{e}(\mathrm{mg} / \mathrm{L})$ is the equilibrium concentration of the dye, $q_{e}$ is $(\mathrm{mg} / \mathrm{g})$ the amount of dye per unit mass of adsorbent at equilibrium time, $K_{L}(\mathrm{~L} / \mathrm{g})$ and $a_{L}(\mathrm{~L} / \mathrm{mg})$ are the Langmuir isotherm constants. By plotting $C_{e} / q_{e}$ against $C_{e}$, it was possible to obtain the value of $K_{L}$ from the intercept which was $1 / K_{L}$ and the value of $a_{L}$ from the slope which was $a_{L} / K_{L}$. The maximum adsorption capacity of the adsorbent $\left(Q_{\max }\right)$ is numerically equal to $K_{L} / a_{L}[16-18]$.

The essential characteristics of the Langmuir isotherm can be expressed in terms of a dimensionless constant or separation factor $\left(R_{L}\right)$ defined by [19]:

$$
R_{L}=\frac{1}{\left(1+a_{L} C_{0}\right)},
$$

where $C_{0}(\mathrm{mg} / \mathrm{L})$ is the initial dye concentration and $a_{L}(\mathrm{~L} / \mathrm{mg})$ is the Langmuir constant related to the energy of adsorption.

The $R_{L}$ value indicates the shape of the isotherm to be either unfavorable $\left(R_{L}>1\right)$, linear $\left(R_{L}=1\right)$, favorable $\left(0<R_{L}<1\right)$, or irreversible $\left(R_{L}=0\right)$.

Freundlich isotherm was also applied for the adsorption of MB. It often represents an initial surface adsorption followed by a condensation effect resulting from extremely strong solute-solute interaction. The linear form of this adsorption model is given in

$$
\log q_{e}=\log K_{F}+\frac{1}{n} \log C_{e}
$$

where $q_{e}(\mathrm{mg} / \mathrm{g})$ is the amount of $\mathrm{MB}$ adsorbed per gram of adsorbent at equilibrium time, $C_{e}(\mathrm{mg} / \mathrm{L})$ is the equilibrium concentration of the dye, and $n$ and $K_{F}((\mathrm{mg} / \mathrm{g})(\mathrm{L} / \mathrm{mg}) 1 / n)$ 
are Freundlich constants related to the intensity of adsorption and adsorption capacity, respectively.

The plot of $\log q_{e}$ versus $\log C_{e} \log$ was employed to generate the intercept value of $K_{F}$ and the slope $1 / n .1 / n$ is a measure of the deviation from linearity of the adsorption. The value of $1 / n$ ranges between 0 and 1 and indicates the degree of nonlinearity between solution concentration and adsorption as follows: if the value of $1 / n$ is equal to unity, the adsorption is linear; if the value is below unity, this implies that adsorption process is chemical; if value is above unity, adsorption is a favorable physical process [20].

2.9.2. Kinetic Modeling. It is important to be able to predict the rate at which contaminant is removed from aqueous solutions in order to design an adsorption treatment plant. In order to investigate the mechanism of adsorption and potential rate controlling steps such as mass transfer and chemical reaction, the kinetics of $\mathrm{MB}$ adsorption on $\mathrm{SL}$ was investigated using the pseudo-first-order, pseudo-secondorder, and intraparticle diffusion kinetic models.

Lagergren proposed a method for adsorption analysis which is the pseudo-first-order kinetic equation of Lagergren $[17,18,21]$ in the following form:

$$
\ln \left(q_{e}-q_{t}\right)=\ln q_{e}-k_{1} \times t
$$

where $q_{e}$ and $q_{t}$ are the amounts of MB adsorbed $(\mathrm{mg} / \mathrm{g})$ at equilibrium and at time $t(\mathrm{~min})$, respectively, and $k_{1}$ is the rate constant of the pseudo-first-order adsorption.

The rate of pseudo-second-order reaction is dependent on the amount of solute adsorbed on the surface of adsorbent and the amount adsorbed at equilibrium. The pseudosecond-order model proposed by Ho and McKay can be represented in the following form [22]:

$$
\frac{d q_{t}}{d t}=k_{2}\left(q_{e}-q_{t}\right)^{2}
$$

where $k_{2}(\mathrm{~g} / \mathrm{mg} \cdot \mathrm{min})$ is the rate constant of pseudo-secondorder model. After integrating (8) for the boundary conditions $q_{t}=0$ at $t=0$ and $q_{t}=q_{t}$ at $t=t$, the following linear form of equation can be obtained:

$$
\frac{t}{q_{t}}=\frac{1}{k_{2} q_{e}^{2}}+\frac{1}{q_{e}} t
$$

The pseudo-second-order rate constant $\left(k_{2}\right)$ and the equilibrium adsorption capacity $\left(q_{e}\right)$ can be determined experimentally from the intercept and slope of the plots of $t / q_{t}$ versus $t[17,18]$.

Half-adsorption time, $t_{1 / 2}$, is defined as the time required for the adsorption to take up half as much SL as its equilibrium value. This time is often used as a measure of the adsorption rate:

$$
t_{1 / 2}=\frac{1}{k_{2} q_{e}} .
$$

The nature of the rate-limiting step in a batch system can also be assessed from the properties of the solute and

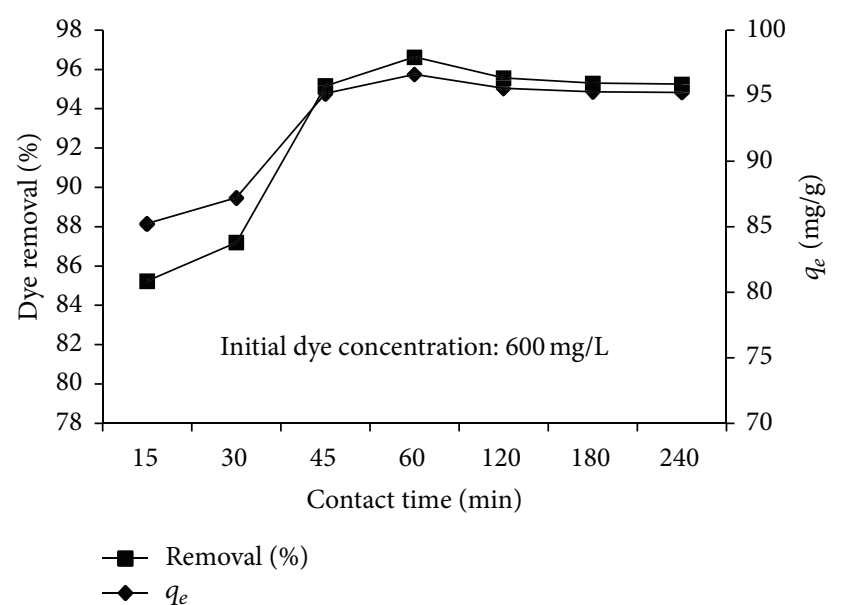

FIGURE 3: Effect of phases contact time on MB adsorption on SL $\left(C_{0}: 600 \mathrm{mg} / \mathrm{L}, t: 25^{\circ} \mathrm{C}, \mathrm{pH}: 7.0\right.$, adsorbent dosage: $\left.6 \mathrm{~g} / \mathrm{L}\right)$.

adsorbent. Weber and Morris [23] stated that if intraparticle diffusion is the rate-controlling step, uptake of the adsorbate varies with the square root of time. The root time dependence, known also as a Weber and Morris plot, may be expressed by

$$
q_{t}=k_{i} t^{1 / 2}+C
$$

where $k_{i}\left(\mathrm{mg} / \mathrm{g} \cdot \mathrm{min}^{1 / 2}\right)$ is an intra-particle diffusion rate constant and $C$ is the intercept. According to (11), a plot of $q_{t}$ versus $t^{1 / 2}$ should be a straight line with a slope $k_{i}$ and intercept $C$ when adsorption mechanism follows the intraparticle diffusion process. Values of intercept give an idea about the thickness of boundary layer. The larger the intercept the greater the contribution of the surface adsorption in the rate controlling step [24].

2.9.3. Thermodynamic Parameters. The free energy change $\left(\Delta G^{0}, \mathrm{~kJ} / \mathrm{mol}\right)$ for adsorption of $\mathrm{MB}$ at $25^{\circ} \mathrm{C}$ was calculated from the following equation [25]:

$$
\Delta G^{0}=-R T \ln K,
$$

where $K$, known as the distribution coefficient of the adsorbate, is equal to $q_{e} / C_{e} . R$ is the gas constant $(8,3145 \mathrm{~J} / \mathrm{molK})$ and $T$ is the temperature in Kelvin (K).

\section{Results and Discussion}

3.1. Effect of Phases Contact Time. Adsorption of MB on SL was carried out at different time intervals (from 15 to $240 \mathrm{~min}$ ) using solution with $600 \mathrm{mg} / \mathrm{L}$ initial dye concentration.

The amounts of adsorbed dye versus contact time are presented in Figure 3. As can be seen from Figure 3 the adsorption process can be considered very fast because a significant amount of $\mathrm{MB}$ was adsorbed on SL within the first $30 \mathrm{~min}$. The maximum amount of MB dye of $96.7 \mathrm{mg} / \mathrm{g}$ was retained from the solution within $1 \mathrm{~h}$ after the start adsorption 


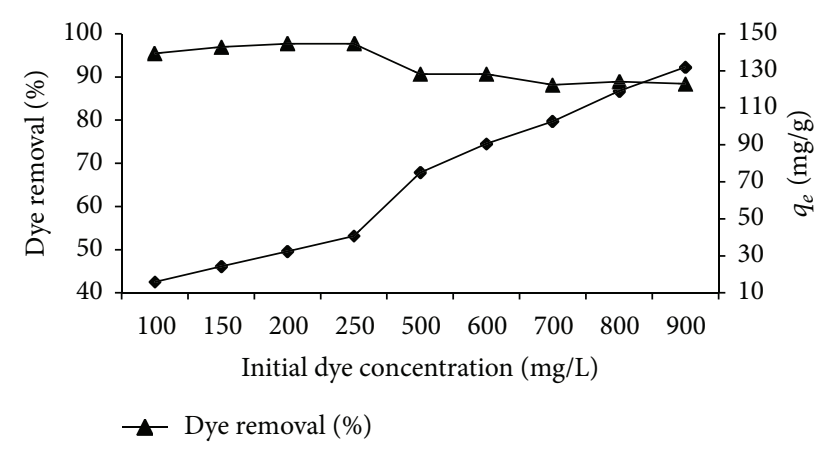

FIGURE 4: Effect of initial MB concentration on MB adsorption on $\mathrm{SL}\left(t: 25^{\circ} \mathrm{C}, \mathrm{pH}: 7.0\right.$, adsorbent dosage: $6 \mathrm{~g} / \mathrm{L}$, and contact time: $2 \mathrm{~h}$ ).

process. After that, the concentration of the MB in liquid phase remained almost constant. However, the experimental data were measured at $2 \mathrm{~h}$ to make sure that full equilibrium was attained. A similar observation was reported for the adsorption of $\mathrm{MB}$ on rise husk and pineapple stem [26].

3.2. Effect of Initial $M B$ Concentration. The effect of initial $M B$ concentration on adsorption process is shown in Figure 4. As can be seen from Figure 4, when the initial dye concentration increased from 100 to $900 \mathrm{mg} / \mathrm{L}$, the loading capacity of SL increased from 12.88 to $130.66 \mathrm{mg} / \mathrm{g}$ and the percentage removal decreased from 96.70 to $88.42 \%$. This is due to increase in the driving force of the concentration gradient, as an increase in the initial concentration. The concentration provides an important driving force to overcome all mass transfer resistance of the dye between the aqueous and solid phases. Hence a higher initial concentration of dye will enhance the adsorption process. However, percentage dye removal rate $(94.57 \%)$ was constant after concentration of $600 \mathrm{mg} / \mathrm{L}$ for MB. Therefore, the following experiments were done by considering $600 \mathrm{mg} / \mathrm{L}$ of $\mathrm{MB}$ concentration.

3.3. Effect of Initial Solution $p H$. The $\mathrm{pH}$ of dye solution plays an important role in the whole adsorption process and particularly on the adsorption capacity, influencing not only the surface charge of the adsorbent, the degree of ionization of adsorbent in the solution, and the dissociation of functional groups on the active sites of the adsorbent, but also the solution dye chemistry.

In the present study the effect of initial solution $\mathrm{pH}$ on $\mathrm{MB}$ adsorption on SL was studied by keeping the dose of $\mathrm{SL}$ and phases contact time constant and varying $\mathrm{pH}$ of the solution from 2 to 9. As shown in Figure 5, the amount of dye adsorbed increases with increasing $\mathrm{pH}$, appreciably up to $\mathrm{pH} 7$ with further increase in $\mathrm{pH}$; there is no significant increase in the amount of dye adsorbed. Adsorption capacity of SL increased from 83 to $95 \mathrm{mg} / \mathrm{g}$ for an increase in $\mathrm{pH}$ from 2 to 7. Maximum removal is observed at $\mathrm{pH}$ 7.0. Hence all further experiments were carried out at $\mathrm{pH}$ 7.0. Similar observations have been reported for the adsorption of MB by giant duckweed [14] and pineapple stem [26]. At lower $\mathrm{pH}$ as

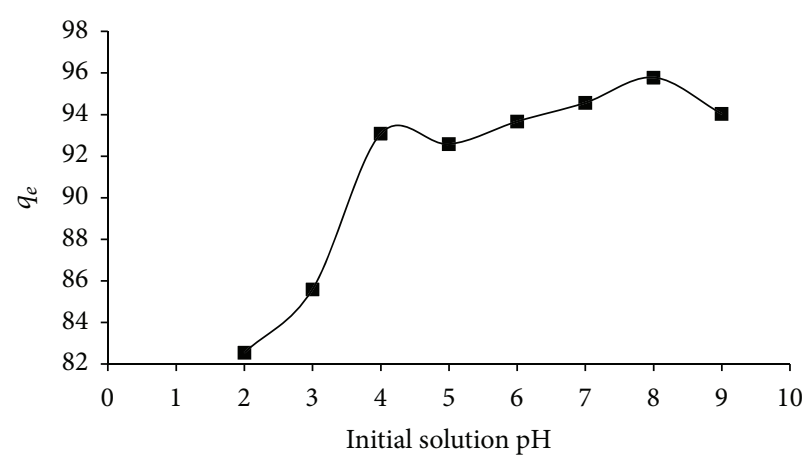

FIGURE 5: Effect of the initial solution $\mathrm{pH}$ on the adsorption of $\mathrm{MB}$ on SL (adsorbent dosage: $6 \mathrm{~g} / \mathrm{L}, C_{0}: 600 \mathrm{mg} / \mathrm{L}, t: 25^{\circ} \mathrm{C}$, and contact time: $2 \mathrm{~h}$ ).

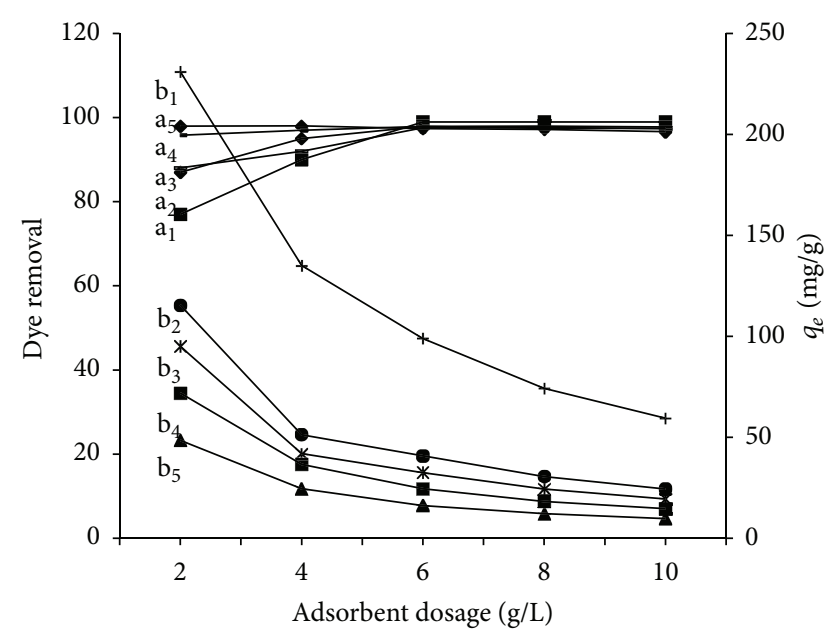

$$
\begin{array}{ll}
\mathrm{a}_{n}: \text { dye removal (\%) } & \mathrm{b}_{n}: q_{e}(\mathrm{mg} / \mathrm{g}) \\
\mathrm{a}_{1}: 600 \mathrm{mg} / \mathrm{L} & \mathrm{b}_{1}: 600 \mathrm{mg} / \mathrm{L} \\
\mathrm{a}_{2}: 250 \mathrm{mg} / \mathrm{L} & \mathrm{b}_{2}: 250 \mathrm{mg} / \mathrm{L} \\
\mathrm{a}_{3}: 200 \mathrm{mg} / \mathrm{L} & \mathrm{b}_{3}: 200 \mathrm{mg} / \mathrm{L} \\
\mathrm{a}_{4}: 150 \mathrm{mg} / \mathrm{L} & \mathrm{b}_{4}: 150 \mathrm{mg} / \mathrm{L} \\
\mathrm{a}_{5}: 100 \mathrm{mg} / \mathrm{L} & \mathrm{b}_{5}: 100 \mathrm{mg} / \mathrm{L}
\end{array}
$$

Figure 6: Effect of SL dose on MB adsorption $\left(C_{0}: 100-600 \mathrm{mg} / \mathrm{L}, t\right.$ : $25^{\circ} \mathrm{C}, \mathrm{pH}: 7.0$, and contact time: $2 \mathrm{~h}$ ).

2 , the surface charge may be positively charged, thus making $\left(\mathrm{H}^{+}\right)$ions compete effectively with dye cations causing a decrease in the amount of dye adsorbed. At higher $\mathrm{pH}$ the surface of SL may be negatively charged which enhances the positively charged dye cations through electrostatic force at attraction.

3.4. Effect of Adsorbent Dose. The effect of the dose of SL on $\mathrm{MB}$ adsorption is presented as \% removal and $\mathrm{mg} \mathrm{MB}$ adsorbed/g SL versus the SL dose in Figure 6. With increase in SL dose, from $2 \mathrm{~g} / \mathrm{L}$ to $10 \mathrm{~g} / \mathrm{L}$ for $\mathrm{MB}$ concentration between 100 and $600 \mathrm{mg} / \mathrm{L}$, the amount of adsorbed MB increases from 76 to $97 \%$. Maximum dye removal was achieved with $6 \mathrm{~g} / \mathrm{L}$ SL dose. After that, the amount of adsorbed per unit mass of adsorbent and percent removal of MB on SL 


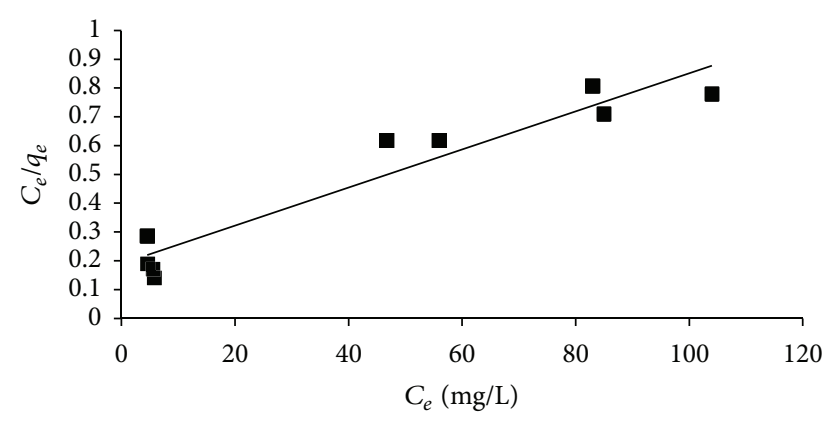

FIgURE 7: Linearized Langmuir isotherm for MB adsorption on SL.

remained almost constant. Hence, $6 \mathrm{~g} / \mathrm{L}$ adsorbent dosage was chosen for all experiments. It is apparent that by increasing the dose of SL, the number of sorption sites available for adsorbent-solute interaction is increased, thereby resulting in the increased percentage of $\mathrm{MB}$ removal from the solution. Decreasing of adsorption capacity, depending on the increase SL dose can be explained with the following two reasons. The increase in adsorbent dose at constant $\mathrm{MB}$ concentration and volume will lead unsaturation of adsorption sites through the adsorption process and secondly may be due to particulate interaction such as aggregation resulting from high adsorbent dose. Such aggregation would lead to a decrease in total surface area of the adsorbent and an increase in diffusional path length [27]. Similar dependence was observed for adsorption of MB onto bamboo-based activated carbon [28].

3.5. Adsorption Isotherm Models. The adsorption isotherm indicates how the adsorbed molecules were distributed between the liquid phase and the solid phase when the adsorption process reaches an equilibrium state. The analysis of the isotherm data by fitting them to different isotherm models is an important step to find the suitable model that can be used for design purpose.

Several models have been published in the literature to describe the experimental data of adsorption isotherms. The Langmuir and Freundlich models are the most frequently employed models.

In this work, both models were used to describe the relationship between the amount of dye adsorbed and its equilibrium concentrations.

3.5.1. Langmuir Isotherm. Langmuir's isotherm model suggests that uptake occurs on homogeneous surface by monolayer adsorption without interaction between adsorbed molecules. The model assumes uniform energies of adsorption onto the surface and no transmigration of adsorbate in the plane of the surface.

When $C_{e} / q_{e}$ is plotted against $C_{e}$, a straight line with slope $a_{L} / K_{L}$ and intercept $1 / K_{L}$ is obtained (Figure 7 ), which shows that the adsorption of MB follows Langmuir isotherm model. The linearized form of Langmuir isotherm is found to be linear over the whole concentration range studied. The value of correlation coefficient $R^{2}(0.92)$ which is greater than
TABLE 1: Comparison of MB adsorption capacity of SL with other reported low cost adsorbent materials.

\begin{tabular}{lcc}
\hline Adsorbent & $Q_{\max }(\mathrm{mg} / \mathrm{g})$ & Reference \\
\hline Sumac Leaves & 151.69 & Present study \\
Garlic peel & 82.64 & {$[8]$} \\
Pineapple stem & 119.05 & {$[13]$} \\
Tamarind fruit shell & 1.72 & {$[28]$} \\
Coconut bunch waste & 70.92 & {$[29]$} \\
Maranti sawdust & 120.48 & {$[30]$} \\
Coffee husk & 90.10 & {$[31]$} \\
\hline
\end{tabular}

0.89 suggests in accord with Jaynes and Boyd [29] that the isotherm could be described by Langmuir model.

Conformation of the experimental data with the Langmuir isotherm model indicates the homogenous nature of SL surface; that is, $\mathrm{MB} / \mathrm{SL}$ adsorption has equal adsorption activation energy; the results also demonstrate the formation of monolayer coverage of dye molecule at the outer surface of SL. The maximum adsorption capacity of SL $\left(Q_{\max }\right)$ and the Langmuir equilibrium constant $\left(K_{L}\right)$, calculated from the slope and the intercept of the linear plot $C_{e} / q_{e}$ versus $C_{e}$, were $151.69 \mathrm{mg} / \mathrm{g}$ and $5.279 \mathrm{~L} / \mathrm{g}$ at $25^{\circ} \mathrm{C}$, respectively. Table 1 lists comparisons of maximum adsorption capacity of $\mathrm{MB}$ dye with various adsorbents. Table 1 shows that the SL studied in this work has very high absorption capacity. The SL used in these experiments proved that had a very high equilibrium adsorption capacity, which determines an adsorption rates very fast and also, a quickly period of time to reach equilibrium. All of these indicate a high degree of affinity between MB and SL.

The values of $R_{L}$ for the studied system at different initial $\mathrm{MB}$ concentrations were found to be in the range of $0.22-0.0031$ and which confirmed that the SL is favorable for adsorption of MB dye under conditions used in this study. Also higher $R_{L}$ values at lower dye concentrations showed that the adsorption was more favorable at lower concentration.

3.5.2. Freundlich Isotherm. The Freundlich isotherm is an empirical adsorption model based on adsorption on heterogeneous surface.

The characteristic Freundlich parameters $\left(K_{F}\right.$ and $\left.1 / n\right)$ calculated from the intercept and slope of the linear plot $\log q_{e}$ versus $\log C_{e}$ (Figure 8) were $11.57(\mathrm{mg} / \mathrm{g})(\mathrm{L} / \mathrm{mg}) 1 / n$ and 0.5027 , respectively.

The $R^{2}$ value (0.9134) is lower than Langmuir's isotherm model. The value of $1 / n(0.5027)$ points out the favorable adsorption conditions. The values of the regression coefficient and $1 / n$ indicate that the data satisfactorily follow both Langmuir and Freundlich models but the Langmuir isotherm fits the experimental data better. The best fit isotherm expressions confirm the monolayer coverage process of MB on SL.

3.6. Adsorption Kinetics. The study of adsorption kinetics describes the solute uptake rate, which controls residence 


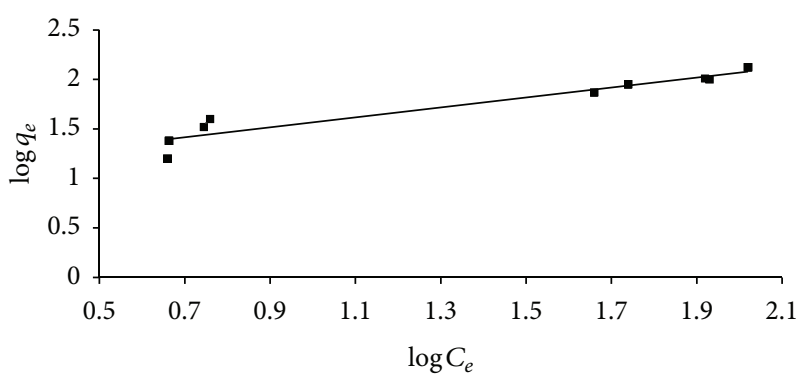

FIGURE 8: Linearized Freundlich isotherm for MB adsorption on SL.

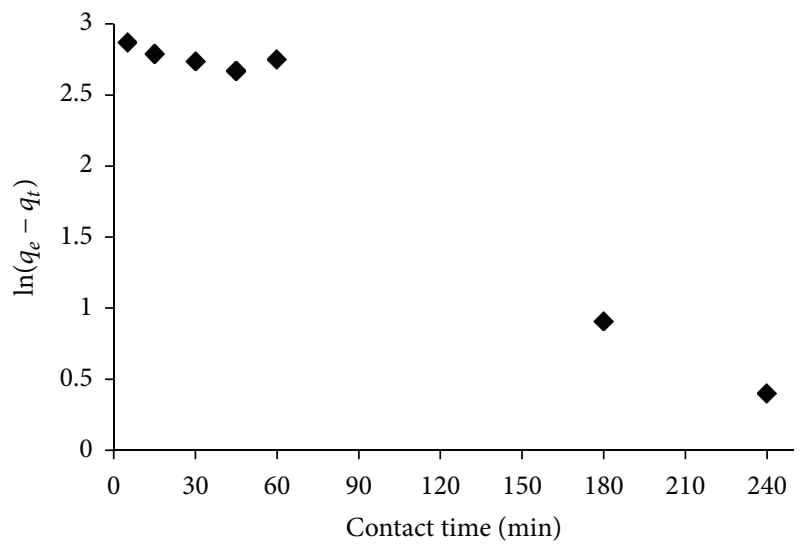

FIGURE 9: Linearized pseudo-first-order kinetic plots for $\mathrm{MB}$ adsorption on SL $\left(C_{0}: 600 \mathrm{mg} / \mathrm{L}\right.$, adsorbent dosage: $\left.6 \mathrm{~g} / \mathrm{L}, \mathrm{pH}: 7.0\right)$.

TABLE 2: Kinetic parameters for MB adsorption on SL (pH: 7.0, $t$ : $25^{\circ} \mathrm{C}$, and $C_{0}: 600 \mathrm{mg} / \mathrm{L}$ ).

\begin{tabular}{lcc}
\hline Kinetic models & Models coefficients & $R^{2}$ \\
\hline Pseudo-first-order & $q_{e}: 21.9 \mathrm{mg} / \mathrm{g}$ & 0.9711 \\
& $k_{1}: 0.01131 \mathrm{~min}^{-1}$ & \\
& $q_{e}: 98.04 \mathrm{mg} / \mathrm{g}$ & \\
Pseudo-second-order & $k_{2}: 2.95 \mathrm{~g} / \mathrm{mg} \cdot \mathrm{min}$ & 0.9977 \\
& $t_{1 / 2}: 0.29 \mathrm{~min}$ & \\
Intraparticle diffusion & $k_{i}: 1.50 \mathrm{mg} / \mathrm{g} \cdot \mathrm{min}^{1 / 2}$ & 0.8109 \\
\hline
\end{tabular}

time of the adsorbate at the solid/solution interface. In order to investigate the mechanism of adsorption various kinetic models have been suggested. The kinetics of $\mathrm{MB}$ adsorption on SL was analyzed using pseudo-first-order (Lagergren model) kinetic, pseudo-second-order (Ho model) kinetic, and intraparticle diffusion $[17,18,23]$ kinetic models. The conformity between experimental data and the model predicted values was expressed by the correlation coefficients $\left(R^{2}\right.$, values close or equal to 1$)$. A relatively high $R^{2}$ values indicate that the model successfully describes the kinetics of dye adsorption.

A plot of $\ln \left(q_{e}-q_{t}\right)$ versus $t$ (Figure 9) should be linear, and rate constant $\left(k_{1}\right)$ and adsorption capacity at equilibrium $\left(q_{e}\right)$ can be determined from the slope and intercept of the plot, respectively. The value of $R^{2}(0.9711)$ indicates that the first-order Lagergren model did not fit the complete range of

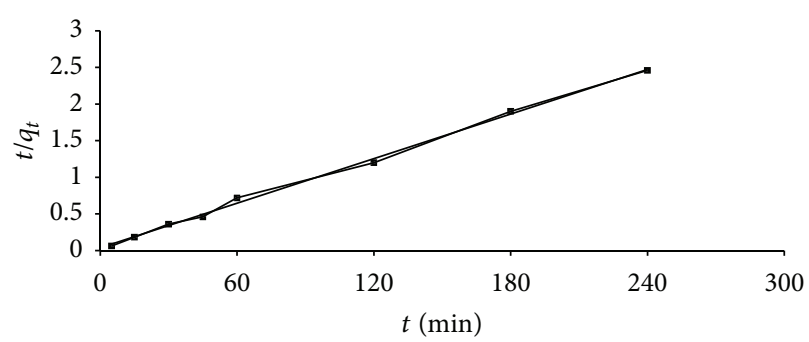

FIGURE 10: Linearized pseudo-second-order-kinetic plots for MB adsorption on SL $\left(C_{0}: 600 \mathrm{mg} / \mathrm{L}\right.$, adsorbent dosage: $6 \mathrm{~g} / \mathrm{L}$, and $\mathrm{pH}$ : $7.0)$.

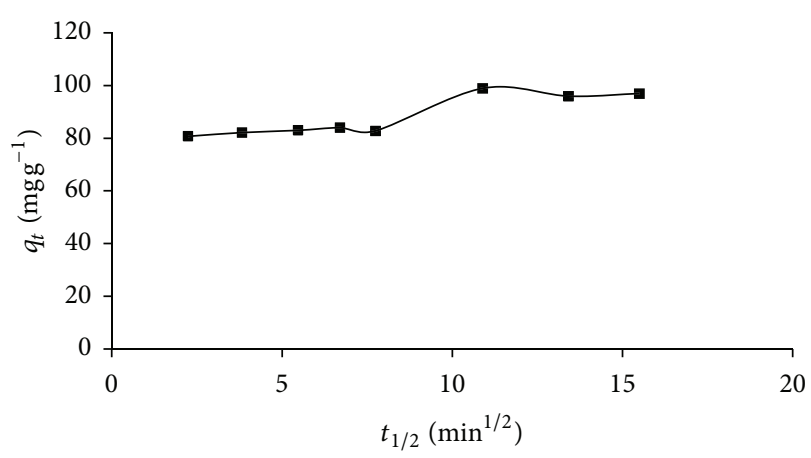

FIGURE 11: Linearized intraparticle diffusion kinetic plots for $\mathrm{MB}$ adsorption on SL $\left(C_{0}: 600 \mathrm{mg} / \mathrm{L}\right.$, adsorbent dosage: $6 \mathrm{~g} / \mathrm{L}$, and $\mathrm{pH}$ : $7.0)$.

the adsorption process well. The parameters of pseudo-firstorder kinetic model are given in Table 2. In many cases the first-order equation of Lagergren does not fit well to whole range of contact time and is generally applicable over the initial stage of the adsorption process [32]. Therefore, the pseudo-second-order kinetic model as shown (9) was used to study the adsorption kinetic of the present system.

Figure 10 shows the fitting plot of the pseudo-secondorder model and the parameters obtained for this model are shown in Table 2. The correlation coefficient $\left(R^{2}=0.9977\right)$ for this kinetic model was observed to be close to 1 . The straight line in plots $t / q_{t}$ versus $t$ showed good agreement of experimental data with the second-order kinetic model suggesting that the adsorption process may be chemisorption.

In order to gain insight into the mechanisms and rate controlling steps affecting the kinetics of adsorption, the kinetic experimental results were fitted to the Weber's intraparticle diffusion $[17,18,21]$. Figure 11 shows the amount of dye adsorbed versus $t_{1 / 2}$ for intraparticle transport of MB by SL. If the regression of $q_{t}$ versus $t_{1 / 2}$ is linear and passes through the origin, then intraparticle diffusion is the sole rate-limiting step. For intraparticle diffusion plots, the first, sharper region is the instantaneous adsorption or external surface adsorption. The second region is the gradual adsorption stage where intraparticle diffusion is the rate limiting. In some cases, the third region exists, which is the final equilibrium stage where intraparticle diffusion starts to slow down due to the extremely low adsorbate concentrations 
left in the solutions [33]. As seen from Figure 11 and Table 2, the plots were not linear $\left(R^{2}=0.81\right)$ over the whole time range, implying that more than one process affected the adsorption.

However, the linear plots did not pass through the origin (the plots have intercept of $75.8 \mathrm{mg} / \mathrm{g}$ ), indicating that intraparticle diffusion was not only rate controlling step and that some other mechanisms also play an important role.

3.7. Gibbs Free Energy Change. The free energy change $\left(\Delta G^{0}\right)$ for adsorption at $25^{\circ} \mathrm{C}$ was calculated using (12) and found to be $-18.38 \mathrm{~kJ} / \mathrm{mol}$. The negative value of $\Delta G^{0}$ indicated the feasibility and spontaneous nature of $\mathrm{MB}$ adsorption and confirmed affinity of SL for the MB.

\section{Conclusion}

In this study adsorption of $\mathrm{MB}$ from aqueous solution on SL has been studied. Adsorption of MB was found to be dependent on initial $\mathrm{pH}$ of solution, adsorbent dose, initial $\mathrm{MB}$ dye concentration, and phases contact time. The $6 \mathrm{~g} / \mathrm{L}$ of adsorbent dose proved to be effective for discoloration of a solution of MB having $600 \mathrm{mg} / \mathrm{L}$. The adsorption equilibrium is achieved in $60 \mathrm{~min}$. The percentage of removal increased with the increasing adsorbent dose, initial solution $\mathrm{pH}$, and phases contact time and decreased with increasing concentration. The value of the monolayer saturation capacity of Sumac Leaves $151.69 \mathrm{mg} / \mathrm{g}$ was comparable to the adsorption capacities of some other adsorbent materials for MB dye. Value of $R_{L}$ in the range of $0-1$ confirmed that the SL is favorable for adsorption of $\mathrm{MB}$ dye. According to the $R^{2}$ and $1 / n$ values, the Langmuir model shows best fit to the equilibrium MB adsorption data than the Freundlich model. The suitability of the Langmuir isotherm model suggests monolayer coverage of dye molecule on the adsorbent surface. The suitability of pseudo-first-order, pseudo-secondorder, and intraparticle kinetic models for the adsorption of $\mathrm{MB}$ on SL were also discussed. The kinetic modeling studies have shown that the experimental data were found to follow pseudo-second-order model. The negative value of free energy change indicated the spontaneous nature of adsorption and confirmed affinity of SL for the MB basic dye. It was concluded that SL can be effectively used as adsorbent for the removal of MB from wastewater.

\section{Acknowledgment}

This work was funded by Science Research Project Fund (Project 2011-01-02-KAP10) of Yildiz Technical University, İstanbul, Turkey.

\section{References}

[1] R. Sivaraj, C. Namasivayam, and K. Kadirvelu, "Orange peel as an adsorbent in the removal of Acid violet 17 (acid dye) from aqueous solutions," Waste Management, vol. 21, no. 1, pp. 105110, 2001.
[2] S. P. Raghuvanshi, R. Singh, and C. P. Kaushik, "Adsorption of congo red dye from aqueous solutions using neem leaves as adsorbent," Asian Journal of Chemistry, vol. 20, no. 7, pp. 49945000, 2008.

[3] A. S. ALzaydien, "Adsorption of methylene blue from aqueous solution onto a low-cost natural jordanian tripoli," American Journal of Environmental Sciences, vol. 5, no. 3, pp. 197-208, 2009.

[4] K. G. Bhattacharya and A. Sharma, "Kinetics and thermodynamics of Methylene Blue adsorption on Neem (Azadirachta indica) leaf powder," Dyes and Pigments, vol. 65, no. 1, pp. 5159, 2005.

[5] S. Chowdhury and P. D. Saha, "Biosorption of methylene blue from aqueous solutions by a waste biomaterial: hen feathers," Applied Water Science, vol. 2, pp. 209-219, 2012.

[6] K. V. Kumar, "Optimum sorption isotherm by linear and nonlinear methods for malachite green onto lemon peel," Dyes and Pigments, vol. 74, no. 3, pp. 595-597, 2007.

[7] S. Senthilkumaar, P. R. Varadarajan, K. Porkodi, and C. V. Subbhuraam, "Adsorption of methylene blue onto jute fiber carbon: kinetics and equilibrium studies," Journal of Colloid and Interface Science, vol. 284, no. 1, pp. 78-82, 2005.

[8] B. H. Hameed and A. A. Ahmad, "Batch adsorption of methylene blue from aqueous solution by garlic peel, an agricultural waste biomass," Journal of Hazardous Materials, vol. 164, no. 2-3, pp. 870-875, 2009.

[9] M. C. Ncibi, B. Mahjoub, and M. Seffen, "Kinetic and equilibrium studies of methylene blue biosorption by Posidonia oceanica (L.) fibres," Journal of Hazardous Materials, vol. 139, no. 2, pp. 280-285, 2007.

[10] G. Palma, J. Freer, and J. Baeza, "Removal of metal ions by modified Pinus radiata bark and tannins from water solutions," Water Research, vol. 37, no. 20, pp. 4974-4980, 2003.

[11] M. Özacar, C. Soykan, and I. A. Şengil, "Studies on synthesis, characterization, and metal adsorption of mimosa and valonia tannin resins," Journal of Applied Polymer Science, vol. 102, no. 1, pp. 786-797, 2006.

[12] A. Zalacain, M. Prodanov, M. Carmona, and G. L. Alonso, "Optimisation of extraction and identification of gallotannins from sumac leaves," Biosystems Engineering, vol. 84, no. 2, pp. 211-216, 2003.

[13] A. Uçer, A. Uyanık, and F. Ş. Aygün, "Adsorption of $\mathrm{Cu}(\mathrm{II})$, $\mathrm{Cd}(\mathrm{II}), \mathrm{Zn}(\mathrm{II}), \mathrm{Mn}(\mathrm{II})$ and $\mathrm{Fe}(\mathrm{III})$ ions by tannic acid immobilized activated carbon," Seperation and Purification Technology, vol. 47, pp. 113-118, 2006.

[14] P. Waranusantigul, P. Pokethitiyook, M. Kruatrachue, and E. S. Upatham, "Kinetics of basic dye (methylene blue) biosorption by giant duckweed (Spirodela polyrrhiza)," Environmental Pollution, vol. 125, no. 3, pp. 385-392, 2003.

[15] C. Tien, Adsorption Calculations and Modeling, ButterworthHeinemann, Boston, Mass, USA, 1994.

[16] G. Crini, H. N. Peindy, F. Gimbert, and C. Robert, "Removal of C.I. Basic Green 4 (Malachite Green) from aqueous solutions by adsorption using cyclodextrin-based adsorbent: kinetic and equilibrium studies," Separation and Purification Technology, vol. 53, no. 1, pp. 97-110, 2007.

[17] G. Limousin, J.-P. Gaudet, L. Charlet, S. Szenknect, V. Barthès, and M. Krimissa, "Sorption isotherms: a review on physical bases, modeling and measurement," Applied Geochemistry, vol. 22, no. 2, pp. 249-275, 2007. 
[18] G. Alberti, V. Amendola, M. Pesavento, and R. Biesuz, "Beyond the synthesis of novel solid phases: review on modelling of sorption phenomena," Coordination Chemistry Reviews, vol. 256, no. 1-2, pp. 28-45, 2012.

[19] T. W. Weber and R. K. Chakravorti, "Pore and solid diffusion models for fixed-bed adsorbers," Journal of American Institute of Chemical Engineers, vol. 20, no. 2, pp. 228-238, 1974.

[20] T. B. Iyim and G. Güçlü, "Removal of basic dyes from aqueous solutions using natural clay," Desalination, vol. 249, no. 3, pp. 1377-1379, 2009.

[21] S. Lagergren, "About the theory of so-called adsorption of soluble substances," Kungliga Svenska Vetenskapsakademies Handlingar, vol. 24, no. 4, pp. 1-39, 1898.

[22] Y.S. Ho and G. McKay, "A Comparison of chemisorption kinetic models applied to pollutant removal on various sorbents," Process Safety and Environmental Protection, vol. 76, no. 4, pp. 332-340, 1998.

[23] W. J. Weber and J. C. Morris, "Kinetics of adsorption on carbon from solution," Journal of the Sanitary Engineering Division, vol. 89, pp. 31-59, 1963.

[24] N. Kannan and M. M. Sundaram, "Kinetics and mechanism of removal of methylene blue by adsorption on various carbons-a comparative study," Dyes and Pigments, vol. 51, no. 1, pp. 25-40, 2001.

[25] S. Karagöz, T. Tay, S. Uçar, and M. Erdem, "Activated carbons from waste biomass by sulfuric acid activation and their use on methylene blue adsorption," Bioresource Technology, vol. 99, no. 14, pp. 6214-6222, 2008.

[26] B. H. Hameed, R. R. Krishni, and S. A. Sata, "A novel agricultural waste adsorbent for the removal of cationic dye from aqueous solutions," Journal of Hazardous Materials, vol. 162, no. 1, pp. 305-311, 2009.

[27] E. N. El Qada, S. J. Allen, and G. M. Walker, "Adsorption of basic dyes onto activated carbon using microcolumns," Industrial and Engineering Chemistry Research, vol. 45, no. 17, pp. 6044-6049, 2006.

[28] B. H. Hameed, A. T. M. Din, and A. L. Ahmad, "Adsorption of methylene blue onto bamboo-based activated carbon: kinetics and equilibrium studies," Journal of Hazardous Materials, vol. 141, no. 3, pp. 819-825, 2007.

[29] W. F. Jaynes and S. A. Boyd, "Hydrophobicity of siloxane surfaces in smectites as revealed by aromatic hydrocarbon adsorption from water," Clays \& Clay Minerals, vol. 39, no. 4, pp. 428-436, 1991.

[30] P. Saha, "Assessment on the removal of methylene blue dye using tamarind fruit shell as biosorbent," Water, Air, and Soil Pollution, vol. 213, no. 1-4, pp. 287-299, 2010.

[31] B. H. Hameed, D. K. Mahmoud, and A. L. Ahmad, "Equilibrium modeling and kinetic studies on the adsorption of basic dye by a low-cost adsorbent: coconut (Cocos nucifera) bunch waste," Journal of Hazardous Materials, vol. 158, no. 1, pp. 65-72, 2008.

[32] Y. S. Ho and G. McKay, "Pseudo-second order model for sorption processes," Process Biochemistry, vol. 34, no. 5, pp. 451465, 1999.

[33] W. H. Cheung, Y. S. Szeto, and G. McKay, "Intraparticle diffusion processes during acid dye adsorption onto chitosan," Bioresource Technology, vol. 98, no. 15, pp. 2897-2904, 2007. 

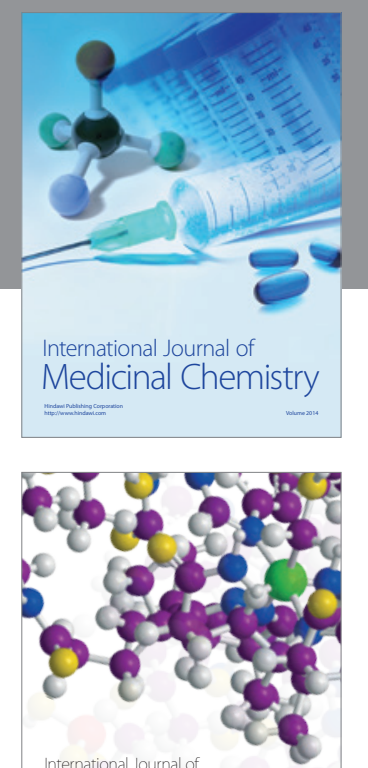

\section{Carbohydrate} Chemistry

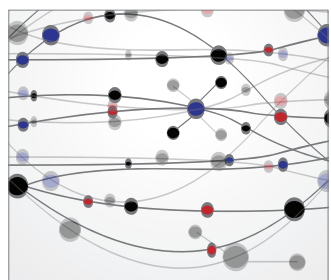

The Scientific World Journal
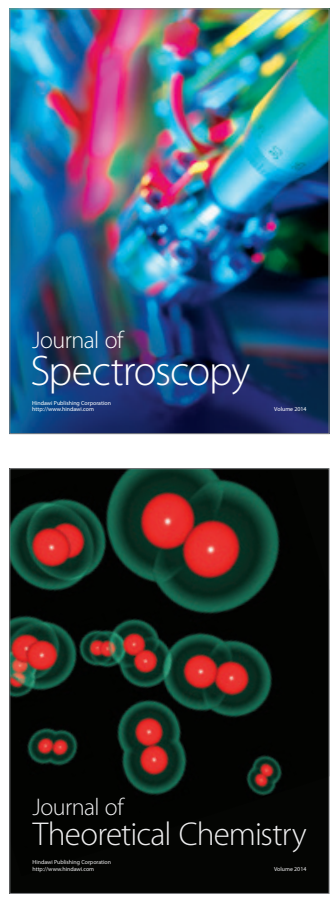
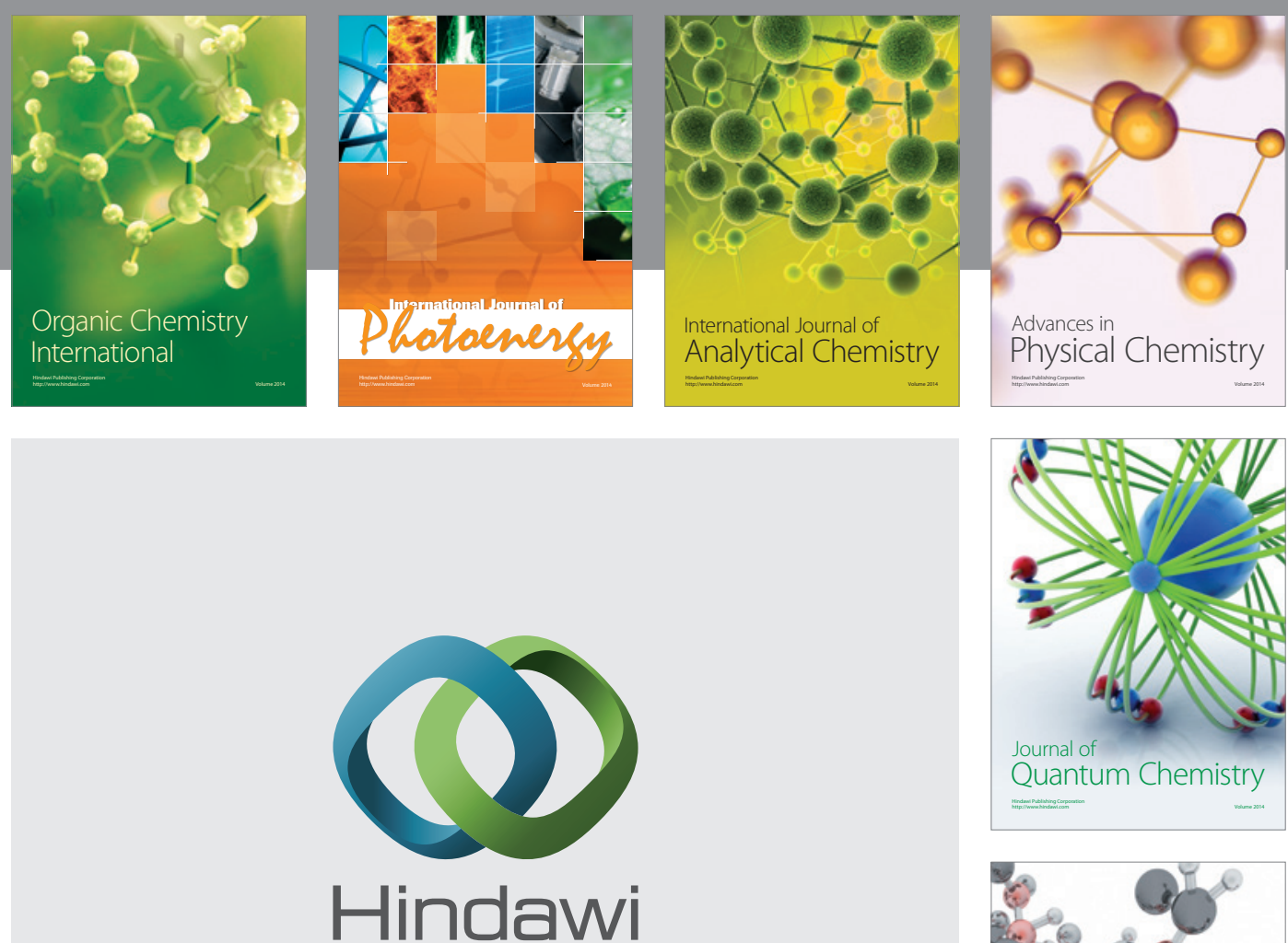

Submit your manuscripts at

http://www.hindawi.com

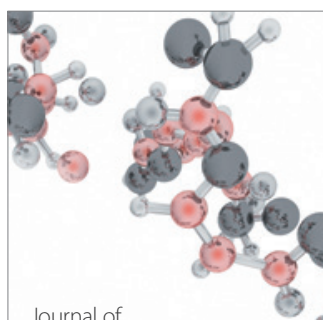

Analytical Methods

in Chemistry

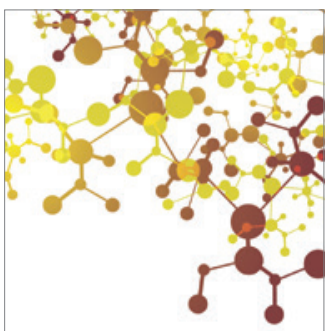

Journal of

Applied Chemistry

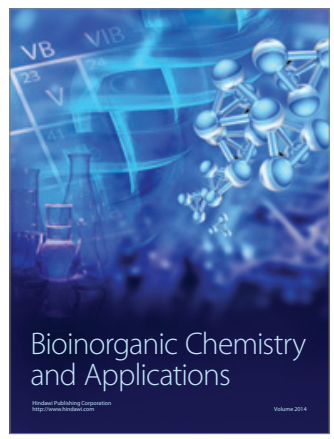

Inorganic Chemistry
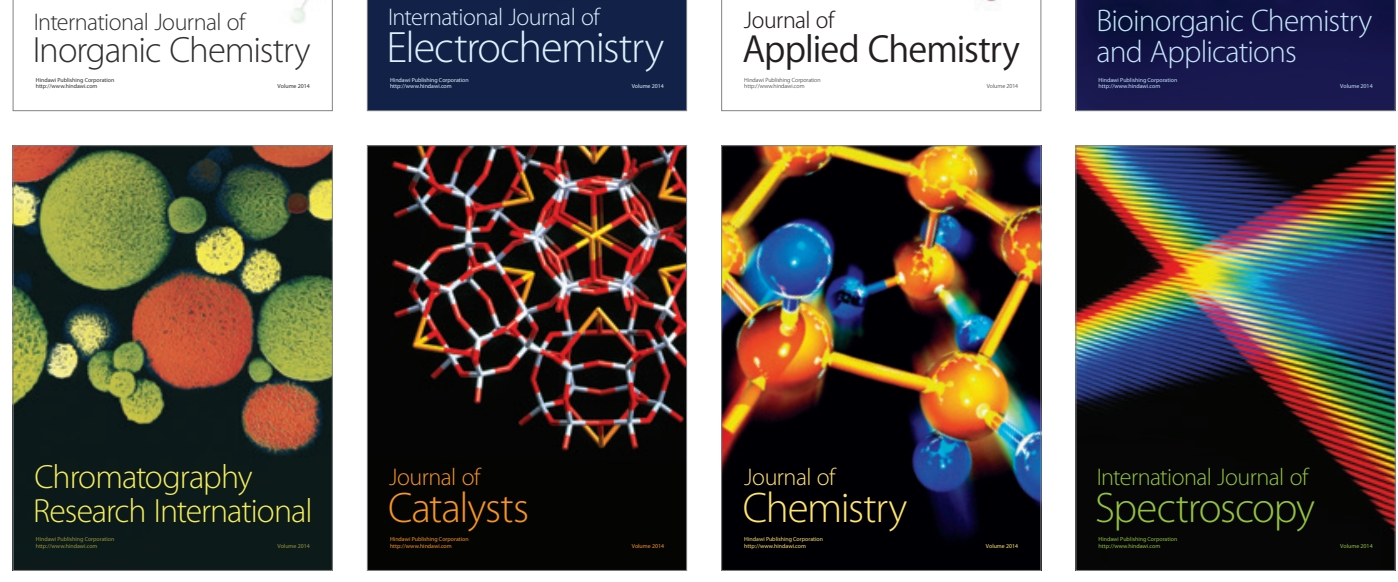